\title{
Los dilemas de la paz y la justicia. Notas a propósito del llamado a la reconciliación del general Pedro Alcántara Herrán en la guerra civil de 1859-1862*
}

Recibido: 02/08/2020 | Revisado: 19/11/2021 | Aceptado: 11/01/2020

DOI: 10.17230/co-herencia.18.34.13

\author{
Liliana María López Lopera** \\ llopezlo@eafit.edu.co \\ Manuel Alberto Alonso Espinal*** \\ manuel.alonso@udea.edu.co
}

\begin{abstract}
Resumen Utilizando como referencia la Carta política escrita por el general Pedro Alcántara Herrán a Bartolomé Calvo, en el contexto de la guerra civil colombiana de 1859-1862, en este artículo se analizan las relaciones existentes entre la negociación de la paz, la justicia y la regulación de la guerra. Se pretende mostrar que en el siglo XIX las iniciativas políticas para evitar, suspender, limitar o terminar la guerra fueron tan abundantes y plurales como los levantamientos y las confrontaciones armadas. Además de presentar la especificidad anómala del caso colombiano, donde históricamente coexisten y se entremezclan los llamados a la guerra con los propósitos de la reconciliación, el artículo rescata, para la actualidad, un documento histórico que sintetiza el lenguaje de la paz, la concordia y la reconciliación en una de las más largas y crueles guerras civiles decimonónicas.
\end{abstract}

\section{Palabras clave:}

Colombia, siglo XIX, paz, negociación, justicia, reconciliación.
* Este artículo hace parte de la investigación Discursos, estrategias y relatos de paz en el siglo XIX colombiano, 18101862, financiada por la Universidad EAFIT y el Comité para el Desarrollo de la Investigación (CODI), de la Universidad de Antioquia.

** Doctora en Humanidades, profesora investigadora de la Universidad EAFIT, Medellín-Colombia. ORCID: 0000-00018613-2255. 
Dilemmas of Peace and Justice: Notes on the Call for Reconciliation by General Pedro Alcántara Herrán in the Civil War of 18591862

\begin{abstract}
Using the political letter written by General Pedro Alcántara Herrán to Bartolomé Calvo as a reference, in the context of the Colombian civil war of 1859-1862, this article analyzes the relation between peace negotiations, justice, and regulating war. In the 19 th century, the political initiatives to avoid, suspend, limit or end the war were as abundant and multiple as the uprisings and armed confrontations. In addition to presenting the anomalous specific case of Colombia, where, historically, calls for war coexist and intermingle with the goals of reconciliation, the article regains a historical document for the present day that synthesizes the language of peace, harmony, and reconciliation in one of the longest and most cruel civil wars of the 19th century.
\end{abstract}

\section{Key words:}

Colombia, 19th century, peace, negotiation, justice, reconciliation.
*** Doctor en Historia, profesor titular del Instituto de Estudios Políticos de la Universidad de Antioquia, Medellín-Colombia. ORCID: 0000-00018356-217X.

Inscrito en la teoría crítica y política de la guerra y teniendo como foco de atención los dilemas de la reconciliación en momentos de transición a la paz, Iván Orozco (2005) afirma que "los caminos básicos para salir de la guerra son dos: la victoria o la negociación. Existen por supuesto caminos intermedios, victorias negociadas y negociaciones que equivalen a victorias. Existen además mil maneras de vencer y de negociar" (p. 252). En un sentido similar, Jorge Giraldo (2009) propone una corrección a las teorías monistas de la guerra justa y sostiene que "la victoria nunca es perentoria" (p. 288), pues una guerra civil que sea percibida como una lucha entre enemigos absolutos "es un enfrentamiento entre fanatismos ajeno a lo que el 'arte político reclama”' (p. 288). Para este autor, la negociación no significa ausencia de guerra, ni es "pérdida de la enemistad, ni siquiera obstáculo para persistir en doblegar, armas en la mano, la voluntad del contrario, sino simplemente posibilidad del acuerdo de paz" (p. 289).

Referir a dos autores contemporáneos preocupados por las 
condiciones que requiere el ius post bellum, ${ }^{1}$ sirve para presentar una carta escrita por el general Pedro Alcántara Herrán ${ }^{2}$ en el contexto de la guerra civil colombiana de 1859-1862, haciendo un llamado a la conciliación nacional. Ella tiene como destinatario al entonces procurador general de la nación y presidente encargado de la Confederación, Bartolomé Calvo, ${ }^{3}$ y hace parte de las múltiples peticiones que se le hicieron al ejecutivo central para buscar la salida negociada de un conflicto que comenzaba a ser desfavorable, en términos militares, para el Gobierno de la Confederación. En la comunicación, fechada el 31 de marzo de 1861, el general Herrán le recuerda al procurador general los riesgos políticos y morales que entraña llevar una guerra hasta el final, sin tener esperanzas de vencer y sin calcular los efectos nocivos que puede tener en la legitimidad del orden político (Herrán, 1861, p. 95).

Desde la orilla moderada del conservatismo colombiano, este general promovió los valores de la paz y el orden como garantía de la estatalidad y la soberanía inmanente del Estado, buscó alternativas negociadas a la guerra y defendió los principios del ius in bello. En tal sentido, promovió reglas orientadas a limitar y regular las acciones bélicas y puso en marcha varias estrategias para poner fin a las hostilidades desde los inicios de las contiendas civiles. En sus discursos, proclamas, cartas y escritos, Herrán recreaba dos premisas centrales de la teoría política de la guerra justa: la primera, que de los medios, la conducta y las regulaciones bélicas depende la posibilidad de la paz, y la segunda, que los males que causa una guerra civil están, generalmente, en proporción directa con lo que ella dura (Giraldo, 2009; Orozco, 2006; Walzer, 2001).

1 Los principios de la guerra justa se ocupan de la distinción en torno al derecho a la guerra -el ius ad bellum- y de los criterios para limitar y regular sus alcances -el ius in bello-. En la actualidad, a estos dos principios se les adhiere la justicia después de la guerra, es decir, la justicia de los acuerdos de paz y de los procesos de restauración -el ius post bello- (Walzer, 2001, p. 52).

2 La referencia biográfica a Herrán, la edición crítica y la transcripción de la carta se encuentran en las páginas 409-430 de esta edición de la revista Co-herencia.

3 Jurisconsulto, orador, periodista y poeta colombiano. Senador y candidato a la presidencia del Estado de Bolívar y procurador general de la nación de 1859 a 1861. Con tal carácter ocupó el poder ejecutivo desde el $1^{\circ}$ de abril de 1861 hasta el 18 de junio del mismo año (Ospina, 1927, t. I, p. 403). 
En la comunicación enviada al procurador general de la nación, Pedro Alcántara Herrán anota que la prolongación de la guerra en lapsos indefinidos es más costosa, en términos del derramamiento de sangre de los compatriotas; más ruinosa para la administración pública, el Estado y sus ciudadanos; y más degradada, por la conducta bélica de los guerreros. En sus palabras:

El más alto funcionario de nuestra Confederación, como primer guardián del honor nacional y como principal encargado de la conservación del orden general, tiene la atribución de dirigir la guerra. La Nación le confía lo más sagrado y lo más importante que tiene, -su honor y su vida-, y para que atienda a estos dos objetos, lo inviste de aquella facultad poderosa, bajo una responsabilidad proporcionada á la magnitud de la confianza [...] El Gobierno debe llenar esta obligación, haciendo uso con actividad y energía de cuantos medios están a su alcance, para que pronto se consiga el objeto que se propone, a fin de hacer cesar cuanto antes y con buen éxito la guerra (Herrán, 1901 [1861], pp. 93-94).

El discurso conciliador del general bogotano tiene mayor significación si se recuerda que a lo largo de su vida ocupó en varias ocasiones la Comandancia General del Ejército y tuvo que enfrentar, en algunas de las guerras civiles decimonónicas, a los jefes rebeldes. No obstante, esta condición de ministerial o legitimista, como se decía en aquella época, no fue un obstáculo para que mostrara a lo largo de su carrera política y militar una igual disposición para emprender batallas o firmar acuerdos de paz, y que defendiera una postura política que otorgaba el carácter de guerra a la guerra civil y la condición de enemigos públicos y relativos a los alzados en armas. Así lo había demostrado en la Guerra de los Supremos (1839-1842) con la firma de las esponsiones de los Árboles y Sitio Nuevo (Prado, 2018; Uribe de Hincapié y López, 2006), y así lo refrendó en la guerra civil de 1859-1862 con los arreglos de paz firmados el 26 de marzo de 1861 en Cartagena, con el general insurrecto Juan José Nieto (Nieto, 1862, p. 77).

Un número importante de los estudiosos de la historia política del siglo XIX colombiano aceptan que los referentes de identidad colectiva se han tejido en torno al eje de la guerra, y que las confrontaciones civiles configuraron las formas de la dominación 
política y la estructura adoptada por el campo estatal (González, 1997; Uribe de Hincapié, 2001). Aunque el país no enfrentó durante ese siglo guerras importantes de carácter interestatal, las guerras civiles constituyeron un elemento central en el proceso de autoafirmación y singularización de la nación. En la Colombia del siglo XIX, además de la guerra de independencia, es posible identificar ocho grandes guerras civiles de alcance nacional y decenas de guerras locales. Entre las primeras figuran la Guerra de los Supremos, las guerras civiles de 1851, 1854, 1859-1862, 1876-1877, 1884-1885, 1895, y la Guerra de los Mil Días. La enumeración de las segundas es mucho más difícil, pues no existen acuerdos sobre su número y contenido. No obstante, Gustavo Arboleda identificó 54 movimientos armados que tenían por finalidad derrocar al gobierno nacional o local (Arboleda, 1907, pp. 59-60).

Al compás de esa historia de guerras civiles, enfrentamientos provinciales y conflictos locales, se enunciaron un gran número de estrategias políticas orientadas a someter el uso de las armas al juicio sobre lo justo y lo injusto, y se desplegaron un amplio conjunto de mecanismos dirigidos a hacer las guerras negociables o a encontrar soluciones, más o menos rápidas, pacíficas y decorosas, para ponerles fin. Dentro de estos últimos se encuentran las acciones diplomáticas, las declaratorias de neutralidad, las capitulaciones, las esponsiones, los armisticios, las rendiciones, las amnistías abiertas e incondicionales, las amnistías cerradas y condicionales, y los perdones penales y disuasivos.

La historiografía sobre las guerras civiles muestra a Colombia como una nación en permanente guerra civil, con altos y persistentes niveles de violencia, caos y desorden. En algunos estudios recientes, esa historiografía también destaca la amplia gama de negociaciones, transacciones formales e informales, acuerdos políticos, discursos pacifistas e instrumentos jurídicos implementados durante aquel siglo para superar los conflictos (Camacho et al., 2018; Guerrero, 2016; Orozco, 2006; Sánchez, 2001; Uribe de Hincapié, 2011). El propósito de este texto es contribuir a esos estudios sobre la paz y rescatar algunos de los lenguajes políticos sobre la indulgencia, el perdón y la clemencia presentes en el siglo XIX. Utilizando como 
pretexto el documento histórico escrito por el general Pedro Alcántara Herrán, el artículo analiza las relaciones existentes entre la negociación de la paz, la justicia y la regulación de la guerra. Lo que se quiere enfatizar es que las iniciativas políticas para evitar, suspender, limitar o terminar la guerra fueron tan abundantes y variadas como los levantamientos y las confrontaciones armadas. Además de mostrar la especificidad anómala del caso colombiano, donde históricamente coexisten y se entremezclan los llamados a la guerra con los propósitos de la reconciliación, el artículo pretende rescatar, para la actualidad, un documento que sintetiza el lenguaje de la paz, la concordia y la conciliación en una de las más largas y crueles guerras civiles decimonónicas.

Con esto en mente, en un primer momento se presenta el contexto histórico en el cual se inscribe la Carta Política enviada por el general Herrán a Bartolomé Calvo. Después, en dos apartados, nos detenemos en tres asuntos que aparecen referenciados en el texto del general Herrán y que constituyen una novedad para la época y una anticipación de algunos postulados revisionistas de las teorías contemporáneas de la guerra justa, esto es, la naturaleza política de la guerra civil, el reconocimiento del rebelde como enemigo relativo y la dualidad existente entre la reconciliación y la justicia retaliativa.

\section{La guerra civil de 1859-1862: de los campos de batalla a los intentos de negociación}

Toda guerra civil es un acontecimiento particular, de corta duración, que se produce por la acción u omisión de sujetos que actúan de acuerdo con las condiciones impuestas por las circunstancias específicas e irrepetibles de su tiempo. A pesar de presentar hilos de continuidad y elementos comunes con otras confrontaciones armadas, la guerra civil de 1859-1862 fue un evento único que respondía a la compleja sumatoria de conflictos locales, provinciales e interestatales provocados por el despliegue del modelo de organización política de corte federal y la marcada debilidad de la estructura fiscal del Estado y de sus aparatos coercitivos. 
Cuando se miran los estudios y los relatos sobre una guerra civil en particular, con bastante frecuencia es posible identificar una fecha aproximada sobre su comienzo y un momento más o menos preciso sobre su finalización. La primera está relacionada con aquel evento formal y público en el cual un actor no estatal proclama la guerra, o con aquel episodio por el cual el gobierno realiza un pronunciamiento declarando turbado el orden público. El segundo corresponde con aquel suceso, casi siempre una batalla, una capitulación, una amnistía o un perdón general, en el cual alguno de los protagonistas notifica el triunfo sobre el enemigo y el restablecimiento del orden constitucional.

El inicio de la guerra civil de 1859-1862 se ubica, oficialmente, el 3 de septiembre de 1859, fecha en la cual el presidente de la Confederación, Mariano Ospina Rodríguez, expidió un decreto que declaró en estado de guerra a la República (Gaceta Oficial, 1859, p. 473), reorganizó al ejército y nombró al general Pedro Alcántara Herrán como su comandante. Y su finalización se da con la derrota de los ejércitos antioqueños comandados por Rafael María Giraldo en la batalla de Santa Bárbara de Cartago el 18 de septiembre de 1862 y con la posterior firma del documento de rendición de Antioquia ante el general Mosquera, el 13 de octubre de 1862 en la Aldea de María.

Cualquier estudio o investigación sobre esta guerra civil se debe anclar en esa temporalidad. Esas dos fechas le otorgan el sentido y la sincronía necesaria para identificarla como un acontecimiento histórico particular y específico. Sin embargo, las guerras civiles se tejen en el tiempo de múltiples maneras y, en la reconstrucción de sus tramas, el investigador puede trascender el relato cronológico, expandirlo y contraerlo temporalmente, pues las guerras civiles son enfrentamientos bastante complejos y menos homogéneos de lo que las cronologías, los discursos y las narraciones muestran.

En el caso específico de esta confrontación armada, esta posibilidad de expandir o contraer los tiempos aparece en el trabajo La guerra por las soberanías (Uribe de Hincapié y López (2008a), en el que se identifican tres grandes momentos de su desarrollo. El primero de ellos hace referencia a los levantamientos armados ocurridos entre 1857 y 1859 en los Estados federales de Magdalena, 
Santander, Bolívar y Cauca. Este primer momento está marcado por el despliegue de un amplio número de conflictos de naturaleza esencialmente local, entre los que es posible identificar viejas disputas entre provincias y localidades en torno al ordenamiento territorial, resistencias locales a las reformas liberales, enfrentamientos entre nacientes espacios subregionales y locales, pugnas partidistas en las localidades por el control de la administración del Estado, conflictos y querellas por el control electoral de las asambleas de los Estados federales, confrontaciones entre ciudades por la definición del centro hegemónico, desórdenes civiles que impugnaban los resultados electorales, y rencillas personales y conflictos privados de múltiple naturaleza.

En medio de las enconadas disputas y discusiones entre el gobernador del Estado del Cauca, Tomás Cipriano de Mosquera, y el presidente de la Confederación, Mariano Ospina Rodríguez, en torno a la soberanía de los Estados, ${ }^{4}$ el país comenzó a evidenciar el tránsito hacia una situación en la cual se articulaban esos desórdenes civiles locales con viejos conflictos políticos para producir una confrontación de alcance nacional. El segundo momento de la guerra se desarrolló entre el 3 de septiembre de 1859, cuando se declaró el estado de guerra en la República, y el 18 de julio de 1861, cuando se produce la toma de Bogotá por parte del general Mosquera, el derrocamiento del gobierno conservador que para entonces ejercía el procurador Bartolomé Calvo y la instauración del gobierno provisorio.

Este momento de generalización de la confrontación estuvo ligado a la suma de varios episodios ocurridos en el año de 1860: la promulgación de la resolución del 14 de febrero de la Asamblea Constituyente del Estado de Bolívar manifestando al Gobierno nacional la decisión de defender la soberanía del Estado contra los

$4 \quad$ Discusión provocada por la participación de empleados nacionales en los levantamientos armados del Estado de Santander y por las denuncias realizadas por los gobiernos de los Estados contra un conjunto de leyes expedidas por el Congreso de 1859, de mayoría conservadora, que fueron consideradas por algunos de los gobiernos de esos Estados como inconstitucionales y violatorias de la soberanía federal, así como de las garantías y libertades individuales consagradas en la Constitución de 1858 (Uribe de Hincapié y López, 2008a, pp. 115 y ss.). 
ataques del presidente de la Confederación; la expedición por parte del Gobierno general de la ley de orden público del 16 de abril que elevaba a cinco mil hombres el pie de fuerza de la Confederación; la posesión el 25 de abril de Pedro Alcántara Herrán como general en jefe de los ejércitos de la República; el levantamiento armado regional de figuras del conservatismo del Cauca contra el general Mosquera el 28 de enero; la expedición del decreto del 8 de mayo, con el cual el general Mosquera rompía todo lazo de unión con el Gobierno general y separaba al Estado del Cauca de la Confederación granadina, y la ruptura de la neutralidad de Antioquia y su participación en la guerra enfrentando a los ejércitos mosqueristas.

Entre los grandes acontecimientos bélicos de este segundo momento de la guerra se destacaron la batalla del Oratorio (15 de agosto); el intento de toma de la ciudad de Cartagena por Julio Arboleda y el enfrentamiento por siete días con las tropas de Juan José Nieto (24 de agosto); la batalla de Manizales el 28 de agosto, entre los ejércitos antioqueños al mando de Braulio Henao y las tropas comandadas por el general Mosquera; la toma de Santa Marta por las tropas conservadoras dirigidas por Julio Arboleda (4 de diciembre); la batalla de Subachoque o Campo Amalia (25 de abril de 1861), cerca de la población de La Mesa en Cundinamarca, la más larga y sangrienta de la guerra según el relato de Ángel Cuervo (1984 [1900]); la batalla de Usaquén (13 de junio de 1861) que, con una clara victoria de Mosquera, cambió el curso de la guerra y abrió el camino para la toma final de Bogotá (18 de julio de 1861) por parte de los ejércitos al mando de los generales Tomás Cipriano de Mosquera, José Hilario López y Santos Gutiérrez.

Finalmente, el tercer momento de la guerra hace referencia al desafío lanzado al gobierno provisorio del general Mosquera por la alianza militar del gobernador de Antioquia Rafael María Giraldo con los hermanos Julio y Sergio Arboleda. A esto se sumaba la ofensiva de Leonardo Canal en Santander y las acciones de las guerrillas conservadoras en Cundinamarca. El primer objetivo de esa alianza fue enfrentar a los ejércitos liberales al mando de Eliseo Payán para retomar el control del Estado del Cauca y a partir de allí luchar contra "la dictadura y el gobierno tiránico y usurpador de 
Mosquera" (Canal, 1861). El tercer momento de la guerra civil va desde julio de 1861 hasta la derrota total de las tropas antioqueñas en la batalla de Cartago y su rendición el 13 de octubre de 1862.

Es importante señalar que durante el desarrollo del segundo momento de la guerra, y antes de la toma de Bogotá por parte de Tomás Cipriano de Mosquera, siempre estuvo presente la posibilidad de la firma de acuerdos de paz, esponsiones o armisticios de carácter nacional. Un primer intento de negociación se dio el 27 de agosto de 1860 en Chinchiná, población ubicada entre Santa Rosa de Cabal y Manizales. En ella participaron Braulio Henao, Eliseo Arbeláez y Marceliano Vélez, en representación del ejército antioqueño, y Tomas Cipriano de Mosquera, Liborio Mejía y Simón Arboleda, por parte de los ejércitos caucanos. El acuerdo, propuesto por Mosquera, contemplaba, entre otras cosas, cesar toda hostilidad entre los Estados de Antioquia y el Cauca restableciendo sus relaciones amistosas, mantener a los ejércitos en una neutralidad armada hasta que se restableciera la paz en la Confederación, y suspender las hostilidades y la guerra contra los Estados de Santander, Bolívar y Cauca (Sala de Patrimonio Documental, Universidad de Antioquia, Colección HS, 1860 a 1865 , doc. 72).

Los antioqueños rechazaron esta propuesta y, en respuesta, Mosquera propuso un acuerdo transitorio para regular la guerra por medio del derecho de gentes. Con él buscaba prohibir a los jefes, oficiales y miembros de la tropa cometer actos de atrocidad y asesinar a individuos que se hubieran rendido, no derramar sangre de los fugitivos, dotar de pasaportes a los jefes y oficiales que cayeran presos para que se movilizaran a donde quisieran con el compromiso de no volver a integrar la tropa, dejar en absoluta libertad a los soldados rasos que fueran detenidos para que regresaran a sus casas, y curar y proteger a los heridos (Arboleda, 1990, t. XII, pp. 189-190).

Ante el fracaso de esta primera negociación, el 28 de agosto de 1860 tuvo lugar la batalla de Manizales. Después de ocho horas de combates, en las que el triunfo fue presumiblemente para las huestes antioqueñas, el general Mosquera propuso un cese de hostilidades y la firma de un armisticio. Con la presencia del general Mosquera, Liborio Mejía y Simón Arboleda (del ejército caucano), y el general 
Braulio Henao, Marceliano Vélez, Lucio Estrada y José María Gutiérrez (del ejército antioqueño), se firmó la Esponsión de Manizales. Con ella el gobernador del Estado del Cauca se comprometía a suspender toda hostilidad contra el Gobierno general; revocar el decreto que separaba al Estado del Cauca de la Confederación; someterse al gobierno central, y ofrecer una amnistía completa a todos los comprometidos en los movimientos políticos ocurridos contra el gobierno del Estado del Cauca. Por su parte, el Ejecutivo nacional debía otorgar una amnistía a favor de todos los implicados en los movimientos del Cauca contra las leyes nacionales (Archivo General de la Nación [AGN], SR, Fondo SGM, t. 1091, ff. 326-328).

A diferencia del pacto de Chinchiná, que tenía la connotación de un arreglo político entre dos Estados federales enfrentados, esta esponsión pretendía ser un tratado entre el Estado del Cauca y el Gobierno central. La nueva propuesta de paz fracasó, porque no obtuvo la necesaria refrendación del gobierno de la Confederación. El presidente Ospina se negó a firmarla, porque daba ventajas militares a Mosquera, ignoraba los triunfos de los rebeldes conservadores en Santander y, fundamentalmente, reconocía el carácter de beligerante al general caucano y, por tanto, la justa causa de la guerra civil (Uribe de Hincapié y López, 2008a, pp. 140-143).

Los intentos de negociación incluyeron, además, el tratado de paz formulado por Mosquera el 4 de febrero de 1861, desde la población de Piedras, solicitando que se le reconociera como beligerante y se calificara el levantamiento armado que él encabezaba como una guerra civil; y el armisticio de Chaguaní, firmado el 3 de marzo de 1861, por los ejércitos de la Confederación y los ejércitos federalistas. Este acuerdo volvía sobre el viejo tema del reconocimiento de beligerancia, establecía un cese de hostilidades entre los dos ejércitos, y proponía el nombramiento conjunto de un designado para la presidencia, pues a Ospina solo le quedaba un mes de mandato (Boletín Oficial, 1861).

A estos intentos fallidos de negociación se sumó, antes del ascenso de los ejércitos de Mosquera hacia la sabana de Bogotá, la propuesta de reconciliación y paz enviada por Pedro Alcántara Herrán al procurador general de la nación, un día antes de su posesión 
como presidente encargado de la Confederación. Ella constituía, en lo esencial, la primera propuesta de paz impulsada por miembros afectos y cercanos al Gobierno general, con la intención de lograr un acuerdo estratégico con los insurrectos, en una guerra que ya se presumía perdida. Más allá del carácter conciliador y moderado mostrado por Herrán a lo largo de su carrera política y militar, su propuesta mostraba el rostro de un "civilismo táctico" que respondía al desarrollo negativo que había tenido la confrontación para el Gobierno de la Confederación. ${ }^{5}$

Después del intento de conciliación propuesto por Herrán, vinieron, en su orden: el decreto de indulto expedido por Bartolomé Calvo, el 30 de abril de 1861, ${ }^{6}$ para todos aquellos soldados mosqueristas que entregasen las armas y se integraran al ejército de la Confederación; la amnistía ofrecida por Mosquera el $1^{\circ}$ de junio de ese mismo año para todos aquellos comprometidos en la rebelión contra la causa federalista, exceptuando a los asesinos del general Obando; el intento de negociación entre el arzobispo de Bogotá, Monseñor Herrán, y el general Mosquera antes de la incursión del segundo a la ciudad de Bogotá; y el acuerdo de paz que propuso el general caucano al Estado de Antioquia, en comunicación del 3 de agosto de 1861, si aceptaba al Gobierno provisorio, entraba a formar parte de la Unión y enviaba representantes a la ciudad de Bogotá para acordar el texto de una nueva Constitución.

\section{La guerra civil y la enemistad política}

Carl Schmitt (2010), quien se autodefine como el último representante consciente del ius publicum europaeum y su último profesor

5 Esto es, una correlación de fuerzas desfavorable y un desbalance desproporcionado entre los esfuerzos invertidos por el gobierno conservador para derrocar a los ejércitos rebeldes y el aumento considerable de su poder de resistencia. Asunto de vital importancia para diferenciar la paz de la victoria (Giraldo, 2001, p. 95).

6 Esta propuesta aparece cinco días después de la batalla de Subachoque. Este indulto no cobijaba a aquellos jefes que habían tenido una participación protagónica en la rebelión. A ellos se les concedía una amnistía si se comprometían a salir del territorio granadino durante seis años. 
e investigador en sentido existencial, afirma que la guerra civil es especialmente cruel porque se trata de una guerra entre hermanos y porque se libra dentro de una misma unidad política y entre sujetos sometidos al mismo ordenamiento jurídico, "porque ambos bandos combatientes, al mismo tiempo, afirman y niegan absolutamente esta unidad común [y] ponen al adversario absoluta e incondicionalmente en la ilegalidad, [y porque] implica la sumisión bajo la jurisdicción del enemigo" (2010, p. 67).

Como Carl Schmitt, la mayoría de los conductores políticomilitares de las guerras civiles en el siglo XIX colombiano creían que la soberanía era la máxima expresión de la unidad política, que el Estado era el encargado de producir en el territorio de su dominación una pacificación completa y que la Constitución era la fuente de la cual debía brotar la legitimidad de los gobernantes. Por ello, y siguiendo los principios del moderno derecho de gentes, diferenciaban un doble aspecto de la soberanía: el que trata de las relaciones del Estado con otras naciones -soberanía transeúnte- y el que trata de las relaciones del Estado con sus ciudadanos -soberanía inmanente(Bello, 1840, p. 20). El primero le otorga el atributo político de nación independiente al Estado y, el segundo, la cualidad de nacionales a los ciudadanos del territorio. La condición existencialmente política de la nación dependía, entonces, de su capacidad para establecer la distinción entre un adentro y un afuera, esto es, de la potestad para gobernarse a sí misma y ser reconocida como persona pública por las naciones extranjeras, y del derecho para dictar sus propias leyes, regular los negocios domésticos y ser considerada legítima por los connacionales, conciudadanos y compatriotas (López, 2019, p. 269).

Ministeriales y supremos, legitimistas y federalistas, gobernantes y rebeldes, creían que la guerra debía ser el recurso último en los intentos por resolver los conflictos. Sin embargo, la precariedad de la nación imaginada, la debilidad del Estado, la fragmentación de la soberanía y los rezagos coloniales presentes en la vida política y económica del país, los llevó a considerar la guerra como un mal teleológicamente necesario, es decir, a asumirla como un mal que debía ocurrir, no porque fuera el efecto de una causa, sino porque era el medio privilegiado para alcanzar fines superiores como el progreso 
cívico, moral, material e intelectual de la nación (Bobbio, 2000, p. 65; Camacho Roldán, 1983 [1863], p. 373). Con diferentes énfasis y estrategias narrativas, acordes a una idea de progreso que tiende siempre a lo mejor y mira hacia el futuro, la guerra fue concebida como el motor que favorecía al advenimiento de la civilización y permitía "consumar la ruina completa de una civilización brutal" (Samper, 1984 [1853], p. 457). En este sentido, ella fue entendida como un mal justificado o como un bien, aunque solo fuera un bienmedio en relación con un bien-fin (Bobbio, 2000, p. 66).

Para justificar el uso de las armas, los representantes del gobierno de Mariano Ospina Rodríguez y de la facción rebelde dirigida por el general Mosquera exponen distintos tipos de razones y motivaciones? En la presentación de sus pretensiones, esos protagonistas exhiben situaciones asociadas a la necesidad de reparar o restaurar un derecho agraviado, esto es, la lucha contra un gobierno tiránico, la respuesta a una conspiración, la ruptura del pacto, el desconocimiento de la Constitución, la violación de la autonomía y la soberanía de los Estados, y la usurpación de derechos de los ciudadanos. Con este memorial de agravios se pretende justificar y dotar de legitimidad al levantamiento armado contra el Gobierno o la apelación a las armas para defender el orden institucional.

Las preguntas sobre la legitimidad y justificación de la guerra hacen parte de una teoría que comprende doctrinas filosóficas, políticas y religiosas, preocupadas por evaluar moral y políticamente la guerra, ${ }^{8}$ es decir, si ella es justa o injusta. Esa teoría se ocupa de dos asuntos complejos: las justificaciones que hacen lícito y legítimo emprender una guerra, y la necesidad de poner límites al accionar bélico. Se trata de una teoría crítica porque es "fuertemente restrictiva en cuanto a los motivos para que se inicie una guerra y

7 Quienes se han ocupado del problema de la justificación de la guerra señalan tres casos en los cuales ella podría ser considerada legítima y justa: las guerras defensivas, punitivas y de reparación de agravios. Esta concepción de la guerra como medio se ocupa de exponer las razones morales y políticas que darían forma al ius ad bellum, bajo el supuesto general de que la guerra debe ser sometida a la evaluación sobre lo justo y lo injusto, lo legal y lo ilegal.

8 Cada uno de estos asuntos es bastante controversial. En este artículo solo se pueden enunciar muy brevemente. 
altamente exigente respecto a la conducta de los agentes sociales y sus responsabilidades" (Giraldo, 2009, p. 201).

Esta teoría somete la guerra a dos tipos de juicios que son lógica y jurídicamente independientes. El primero, se relaciona con las razones que se esgrimen para entrar en combate, lo que le otorga el adjetivo de justa o injusta, legal o ilegal a una guerra y, el segundo, concierne a los medios utilizados para llevar a cabo el combate, lo que le concede el calificativo adverbial de librarse justa o injustamente (Walzer, 2001, p. 51). Estos dos asuntos constituyen la esencia más problemática de la teoría de la guerra justa, pues al tratarse de dos tipos de juicios autónomos, puede suceder que una guerra justa se desarrolle injustamente y que una guerra injusta y carente de legitimidad se desarrolle justamente (Walzer, 2001, p. 51).

Los actores de las guerras civiles del siglo XIX colombiano no fueron ajenos a estos debates. Siguiendo las premisas de Emerich de Vattel y don Andrés Bello, expusieron los motivos de conveniencia y utilidad pública para tomar las armas, fueron protagonistas de un amplio conjunto de proyectos y estrategias de negociación, y asumieron la guerra, ante todo, como "una guerra pública entre ciudadanos" (Vattel, 1822, p. 370), ${ }^{9}$ que se llevaba a cabo para salvaguardar la nacionalidad, salvar la patria y proteger la Constitución y el orden republicano. El culto patriótico a los muertos y mártires gloriosos durante las guerras de independencia, y la invención del ciudadano como soldado en los inicios de la vida republicana, dieron forma a un patriotismo combativo y vindicativo a lo largo del siglo, que trastocó las intenciones pacifistas del republicanismo fundador. El mecanismo esencial para restituir el orden y equilibrio preexistentes y para reparar los agravios recibidos era la guerra, esto es, una confrontación civil que se presentaba como justa y legítima ante los coetáneos por los políticos y militares que participaban en ella.

9 La definición de guerra civil ofrecida por Vattel (1822), que fue apropiada y difundida por los conductores políticos de las guerras civiles decimonónicas, reza: "Cuando se forma en el estado un partido que no obedece ya al soberano, y se halla bastante fuerte para resistirle, ó, cuando en una república, la nación se divide en dos facciones opuestas, y de una y otra parte se acude á las armas, es una guerra civil. Algunos reservan esa expresión para distinguir la resistencia justa que los súbditos oponen al soberano, de la ilegítima, de la rebelión, que es una resistencia abierta é injusta" (p. 370). 
El gobierno de turno, con justo título, declaraba y hacía la guerra a los rebeldes, y estos a su vez consideraban justas sus armas, pues ellas eran la respuesta legítima de los ciudadanos frente a gobiernos calificados como inconstitucionales, despóticos y tiránicos. Sin embargo, en los sectores moderados de los dos partidos, también se escucharon las voces de políticos, publicistas $^{10}$ e intelectuales que, sin ser pacifistas radicales, consideraron que los discursos de la indulgencia, la clemencia y la reconciliación podrían tener menos costos y ser más eficaces para restaurar el orden, la legitimidad y la unidad del Estado. ${ }^{11}$ En el desarrollo de la guerra civil de 1859-1862, Pedro Alcántara Herrán representa dicha postura. Particularmente, en la carta dirigida al procurador, el objeto del general no es polemizar sobre el carácter adjetivo de la guerra, sino poner fin a una confrontación armada ruinosa y devastadora que, además, se calculaba perdida. También era objeto de Herrán insistir en que la guerra debía librarse justamente, es decir, atendiendo a los códigos de honor de las sociedades cultas y civilizadas. ${ }^{12}$

Enfrentado a un código penal (1837) que consideraba la rebelión como delito de traición, declaraba a los rebeldes como infames y los condenaba a la pena capital, y en un ambiente político que invisibilizaba y negaba el carácter de guerra de la guerra civil -calificándola como sedición, tumulto y asonada-, y que criminalizaba a los rebeldes -nombrándolos como reos de traición, perturbadores del orden, conspiradores y delincuentes-, el general Herrán defendió la naturaleza política de la confrontación y el tratamiento de

10 Publicista: "El autor que escribe del derecho público ó el muy versado en esta ciencia. Juris publici scriptor". Instituto de Investigación Rafael Lapesa de la Real Academia Española (2013), Mapa de diccionarios [en línea], http://web.frl.es/ntllet.

11 Otro texto emblemático sobre la necesidad de la reconciliación en el país es el discurso Sobre la paz pública, escrito por el jurista y liberal radical Cerbeleón Pinzón (1864) justo en el momento posbélico de esta guerra civil.

12 La guerra civil de 1859-1862 propició la internacionalización del espacio político interior y la incorporación del derecho de gentes en el orden constitucional (Orozco, 2006). Su consagración en la Constitución de los Estados Unidos de Colombia en 1863 instaló en la esfera pública de la época asuntos relativos a la enemistad política y a la necesaria humanización, regulación y contención de las acciones bélicas. El derecho de gentes debía reemplazar el talión y la justicia retributiva que eran usuales en la época. Sin embargo, esto no hizo que esta guerra fuera menos violenta. Por el contrario, ella tuvo episodios de retaliaciones y venganzas legalizadas, trato indigno a prisioneros y atropellos contra la población no combatiente. 
los combatientes como enemigos públicos del Estado. En el caso particular de la misiva enviada al procurador afirmaba que, si bien era perjudicial para el país que hubiera una guerra civil en él, ese mal no se remediaba negando que la hubiera o dándole otro nombre. La única solución posible era ponerle fin. En sus términos simples:

Los enemigos del Gobierno general proclaman principios políticos, cuentan con Estados enteros y con ejércitos organizados, entre ellos hay tres ex-Presidentes, varios Generales y Jefes y muchos ciudadanos que han sido o son Senadores, Representantes o Gobernadores. La revolución tiene poder bastante para exigir condiciones de paz, y no porque se la llame cuadrilla de bandidos deja de tener ese poder. Por decoro de la Nación debemos abstenernos de calificar de bandidos a granadinos que no lo son, y no debemos declarar que la República ha sido gobernada por Presidentes bandidos, elegidos constitucionalmente por nosotros mismos; que en nuestros congresos ha habido muchos bandidos, que nuestros Estados y nuestras Provincias han sido gobernados por bandidos, y que nuestros ejércitos y escuadrones han sido mandados por bandidos. Yo no disculpo el pretexto que se alegó para dar el grito de rebelión ni los atentados que se hayan cometido, pero creo que la dimensión que la revolución ha tomado y el apoyo decidido que le da uno de nuestros partidos políticos en su totalidad, algo significa [...] Si es deshonroso y perjudicial a nuestro país que haya guerra civil en él, ni la honra se recupera, ni los males se curan negando que la haya o dándole otro nombre: el remedio es hacerla cesar (Herrán, 1861, p. 81).

La carta de Herrán a Bartolomé Calvo constituye, sin duda, una respuesta a la visión punitiva y belicista del presidente de la Confederación, Mariano Ospina Rodríguez, y de los sectores más radicales del partido conservador. ${ }^{13}$ Ospina se había negado desde el inicio de la confrontación a reconocer que lo que acontecía en el país era una verdadera guerra civil; argumentó sobre la imposibilidad de aplicar el derecho de guerra a los rebeldes y los tildó de simples perturbadores del orden público y malhechores. En correspondencia privada con fecha del 12 de octubre de 1859, Ospina le presenta al general Tomás Cipriano de Mosquera sus razones para negar la dimensión política de las hostilidades. En un fragmento de la carta se lee:

13 Entre sus máximos exponentes estaban Julio Arboleda, Pastor Ospina, Pedro Gutiérrez Lee y Leonardo Canal. 
El Gobierno general no declara guerra al Estado, ni al distrito, ni al individuo. Cuando se resiste el cumplimiento de la ley, el Gobierno dispone que se juzgue a los que hacen la resistencia: si estos cesan en ella y se someten voluntariamente al juicio y al castigo, todo está terminado, el Gobierno no tiene más que hacer; pero si persistiesen en la comisión del delito, si pretenden sustraerse por la fuerza al juicio y a la pena, entonces el Gobierno usa de la fuerza, no para debelarlos como beligerantes armados, sino para desarmarlos y aprehenderlos como reos, a quienes tiene que poner a disposición del juez respectivo. Aquí no hay declaratoria de guerra ni cosa parecida (Ospina, 1860, p. 8).

El presidente Ospina mantuvo una postura que invisibilizaba, proscribía y criminalizaba la guerra. ${ }^{14}$ De manera consecuente con la negación del estado de guerra y del carácter de enemigos públicos de los rebeldes, se negó también a dar un tratamiento regularizado y acotado a las hostilidades, es decir, desconoció que el rebelde es un ciudadano que rechaza deliberadamente la autoridad del Estado y que su delito no compete al derecho penal sino al derecho de guerra. Esto le sirvió de fundamento para desaprobar todas las medidas de indulgencia y las estrategias de paz que fueron negociadas por sus inferiores con los rebeldes. En una carta enviada al general Mosquera, explica sus razones para negar la firma de la Esponsión de Manizales (8 de septiembre de 1860), en los siguientes términos:

Me habla usted del reconocimiento que los señores generales Posada y Henao hicieron, antes del combate de Manizales, del carácter de beligerante en guerra civil, que usted deseaba asumir [...] El poder ejecutivo no ha considerado en los que han tomado las armas contra el orden general sino individuos en el predicamento en que los colocan las leyes vigentes; y los jefes del ejército no han recibido otra orden respecto de ellos que la de aprehenderlos para someterlos a juicio, y en caso de que opongan resistencia a mano armada, vencer esa resistencia con la fuerza, hasta lograr el fin propuesto (Gaceta Oficial, 1860, p. 578).

14 Invisibilización prescriptiva, proscripción legal, estatalización y criminalización dan forma al conjunto de objeciones que usualmente se exponen con el objeto de ocultar la guerra civil o reducirla a límites que no impliquen la disolución de la unidad política. Giraldo (2001) llama la atención sobre la necesidad de superar estos argumentos para ofrecer un concepto descriptivo y acotado de la guerra civil, de modo que se puedan adoptar conductas normativas que permitan regular este tipo peculiar de conflicto (pp. 193 y ss.). 
El 31 marzo de 1861, en la víspera de la terminación de su mandato y el mismo día del envío de la carta de Herrán al procurador, Ospina hace una alocución en la cual, después de enfatizar el cumplimiento de su deber en el sostenimiento del imperio de la ley, el orden y la paz, se empeña en calificar la guerra civil como delito y a los rebeldes como criminales. Dice Ospina:

La sangrienta lucha que aflige a la República, no es como los traidores lo propalan entre la rebelión y el gobierno, no, ésta es la lucha entre la codicia famélica y rapaz contra la propiedad; el crimen que insolente quiere establecer su impunidad contra la justicia que lo persigue [...] ¿Creéis vosotros que los negros ignorantes del Cauca, que los reos prófugos de las cárceles, que los hombres perdidos de todos los pueblos, que llaman a las filas del ejército de la rebelión, han tomado las armas preocupados por alguna cuestión metafísica sobre las formas de gobierno? No: los móviles de las hordas que rodean a los jefes de la rebelión son la codicia de la ajena propiedad; el sentimiento feroz de la antipatía de raza que saciarán ultrajando y humillando vuestras personas y familias; el odio estúpido del holgazán contra el rico laborioso [...] el rencor del criminal contra la justicia, contra la ley y contra la magistratura que lo condena y persigue (Ospina, 1861, s. p.).

Estos fragmentos resumen muy bien la postura a la que se enfrentaba el general Pedro Alcántara Herrán con su política conciliadora. Él sabía que del tratamiento que se diera a los alzados en armas dependía la paz y la reconciliación en el país. Esto implicaba, necesariamente, superar las posturas que ocultaban y proscribían la guerra civil y convertían a los adversarios en enemigos absolutos e injustos, pues se sabe, por las enseñanzas del autor de El nomos de la Tierra, que, frente a un enemigo percibido como absoluto, no cabe sino la guerra absoluta (Schmitt, 2002).

La divergencia de Herrán con el poder ejecutivo de la Confederación era radical. No se podía aprehender a los rebeldes, tratarlos como si fueran "una partida de malhechores" y someterlos a la justicia penal ordinaria, pues en el país había una guerra civil, sin importar que el presidente le diera otro nombre. Para el general bogotano, la terminación de la guerra, con una paz honrada, exigía el reconocimiento del adversario como iustus hostis (Schmitt, 2002, p. 323), pues esto permitía, como lo recuerda Jorge Giraldo (2009), 
preservar los derechos de los combatientes, aunque estos "sean portadores de motivos que no entendemos ni respetamos" (p. 215). En palabras de Herrán:

Deseo que no haya vencedores ni vencidos, que todos gocemos de iguales garantías, que mis detractores gocen de libertad hasta para calumniar, y que mis enemigos puedan mostrarse altivos, pues jamás he tenido por adversarios a hombres oprimidos o maniatados. Deseo todo esto por el honor de mi país (1861, p. 91).

\section{Los dilemas de la reconciliación: la justicia y la amnistía}

Ya que nuestro Gobierno prefirió, después del triunfo del Oratorio, continuar la guerra, debió aprovechar la ventajosa posición en que se hallaba, haciendo un esfuerzo potente, a todo costo, para vencer completamente la revolución, pero no lo hizo ni había probabilidad de que lo hiciera, porque despreciaba incautamente al enemigo que tenía al frente, y esto era suficiente para conocer que de la política del ciudadano Presidente, no podía esperarse un buen desenlace, ni por medio de un avenimiento, ni por medio de la guerra [...] (1861, p. 87).

Este fragmento muestra el conocimiento que tenía Pedro Alcántara Herrán de los dos únicos caminos existentes para salir de la guerra: la victoria en el campo de batalla o la negociación. Por ello instaba al Gobierno general para que hiciera un uso eficiente de uno de los dos medios que le brindaba la Constitución: emplear la fuerza armada para obtener con ella la restauración del orden público, o buscar medidas conciliatorias. La preferencia del general Herrán eran las soluciones negociadas y la política de reconciliación sobre las victorias militares, pues ellas resultaban menos costosas respecto al derramamiento de sangre.

Del texto de Herrán se pueden inferir dos asuntos de suma importancia para una política de la reconciliación. En primer lugar, la adopción de un sentido negativo y minimalista de la paz, es decir, la inclinación por un concepto genérico de paz referido a la condición contraria al estado de guerra o, siguiendo a Norberto Bobbio (2000), como ausencia de guerra (p. 160); y, en segundo lugar, 
la defensa de la idea según la cual la paz y la victoria no se vinculan necesariamente (Giraldo, 2001, p. 96). Respecto del primer asunto vale la pena insistir en que, si bien el general Herrán promovió a lo largo de su vida pública salidas negociadas y medidas conciliatorias, no se autodefinió como pacifista radical, ni consideró que la paz fuera un valor absoluto. Considerar la paz como un valor absoluto lo hubiera llevado a proscribir la guerra.

Para Herrán, las guerras domésticas constituyen un terrible golpe para el orden institucional y la salud de la patria, sin embargo, ellas también pueden ser un medio para restituir ese orden y defender el honor y la seguridad de la nación (Herrán, 1861, p. 95). Motivos de conveniencia pública como el restablecimiento de la Constitución y del régimen político pueden justificar la guerra, siempre y cuando los males y daños ocasionados no sean superiores a los objetivos buscados. En caso de ser así, la prudencia aconseja abandonar las acciones temerarias y los intereses vanidosos, y limitarse a obtener estos objetivos mediante medidas pacíficas (Herrán, 1861, p. 95). En suma, para el general, la paz no era valor absoluto y suficiente por sí mismo, ni la guerra un mal absoluto.

Respecto al segundo asunto, Herrán tenía claro que a la paz se podía llegar venciendo al enemigo o negociando con él. Su preferencia por los arreglos pacíficos se exacerbó durante esta guerra civil, pues, en dos años de hostilidades, el logro de los objetivos militares y los propósitos políticos la victoria sobre los rebeldes y la restitución del orden confederal- se calculaban improbables. La negociación aparecía, entonces, como una salida táctica, prudente y ajustada a los preceptos del derecho de gentes. Intentar derrotar al oponente a todo trance y a cualquier costo, pasaba por alto que, si el Gobierno tenía éxito, los errores quedaban santificados por el imperio de la fuerza, pero si la revolución triunfaba, los gobernantes elevados por ella quedarían en el peligro de caer por los mismos medios con los que habían subido (Herrán, 1861, p. 89). Esto parecía un vaticinio de lo que sucedería en el tercer momento de la guerra, cuando las guerrillas conservadoras de Norte de Santander, Guasca, Pamplona y García Rovira desafiaron al gobierno provisional instaurado por Tomás Cipriano de Mosquera. Como afirma Iván Orozco Abad (2005), hay 
"negociaciones que equivalen a victorias" (p. 251), y el general Herrán creía que la fuerza irracional y ofuscada era más perniciosa, por sus efectos inmediatos y por sus consecuencias sobre el honor nacional y la legitimidad del orden, que la conciliación y la paz negociada.

Sin entrar en muchos detalles sobre su concepción de lo que debía ser el régimen político, Herrán manifiesta, en su carta, profundas diferencias con la pretensión de los insurrectos de instaurar un régimen de soberanía ilimitada en cada uno de los Estados de la Confederación. Este general defendía un modelo de régimen confederal en el cual tenía primacía la soberanía del gobierno central y la unidad de la nación y, en tal sentido, fue un crítico acérrimo de una posible "duplicación de la soberanía y la estatalidad". Aceptar el programa de soberanía absoluta proclamado por los presidentes y gobernadores de los Estados que se habían levantado en armas contra el Gobierno central era contribuir a la escisión y disolución de la República (Biblioteca Nacional de Colombia [BNC], Fondo Pineda, f. 325, pieza 14, pp. 8-9).

Sin embargo, esta postura propia de su responsabilidad política y de su condición de miembro del partido conservador no fue óbice para que, en relación con la guerra y la paz, defendiera una postura política que daba prioridad a la negociación sobre la guerra y a la amnistía sobre la justicia vindicativa que promulgaban sus copartidarios. Para Herrán, las divergencias partidistas acerca de la forma que debía adoptar el régimen político debían ceder a las consideraciones de conveniencia pública y reconciliación nacional.

La carta política enviada al procurador anticipa muchas de las discusiones actuales sobre la justicia transicional y algunos de los planteamientos de aquellas posturas críticas que establecen claras diferencias entre la justicia retaliativa y la reconciliación. En relación con estos asuntos, en un texto sobre el proceso de transición a la paz que hoy vive Colombia, Giraldo (2017) afirma:

[Al proceso de reconciliación] le estorban la victoria, la regla de la mayoría y la penalidad. La victoria, sobre todo la exhibición de la victoria, porque es una ofensa para los vencidos. La regla de la mayoría, porque es una representación de la victoria en el ámbito asambleario. La penalidad, porque el juicio de los tribunales puede originar nuevas 
guerras [...] Ni victoria, ni mayoría, ni penalidad. El dispositivo para acceder a la reconciliación es la política (p. 52).

Por su parte, Orozco (2005) sostiene que los colombianos no nos hemos percatado del momento en el cual "la palabra amnistía se había convertido para muchos y muy poderosos actores individuales y colectivos [...] en sinónimo de impunidad y de falta de respeto y empatía por las víctimas, y la palabra justicia, en precondición indispensable para alcanzar una paz sostenible" (p. 2).

Un siglo y medio antes, Herrán había presentado argumentos similares, y confrontó a quienes discutían las políticas del perdón y el olvido porque creían que las amnistías e indultos no eran compatibles con la justicia. Para Herrán, el pasado debía dejarse en el olvido y todos los ciudadanos, con prescindencia de sus historias de delitos o heroísmos, debían ser convocados en pie de igualdad para un nuevo comienzo. ${ }^{15}$ La figura jurídico-política de la amnistía era el mecanismo fundamental para impulsar la reincorporación a la vida institucional del partido derrotado. Como otros conductores político-militares, intelectuales y publicistas que participaron en la guerra civil de 1859-1862, ${ }^{16}$ Herrán creía que una reconciliación general de todos los granadinos solo podía lograrse concediendo amnistías amplias e incondicionales por los extravíos que producen las guerras.

Esta idea de la amnistía corresponde, de manera clara, con la función política que tradicionalmente se le otorga, es decir, ser un mecanismo orientado a lograr "un olvido perfecto del pasado" y un instrumento que posibilite la extinción de los motivos que dieron origen a la discordia. La amnistía significa, en la perspectiva de Herrán, una capitulación con el pasado y, en ese sentido, supone que los beligerantes renuncian al derecho de cometer actos de hostilidad, sea por el motivo que ha dado ocasión a la guerra, o por motivos que surjan en su despliegue.

5 Esta idea del olvido perfecto puede resultar inadmisible en el contexto actual, pero en el siglo XIX era ampliamente divulgada y defendida por los actores de la guerra y los dirigentes públicos.

16 José Hilario López, Tomás Cipriano de Mosquera, Cerbeleón Pinzón, Manuel Murillo Toro, Salvador Camacho Roldán, José María Quijano Otero, Ángel Cuervo, Gustavo Arboleda, Manuel Ancízar, José María y Miguel Samper y Aníbal Galindo. 
Desde esta perspectiva, la rebelión y la guerra civil no se consideran delitos, sino errores políticos que deben relegarse a un perpetuo olvido, para "no dejar en el país una huella eterna de rencores y venganzas que lo lleven a la barbarie" (Mosquera, 1862, pp. 187-189). La guerra civil pasa a ser, entonces, "una cosa no avenida" y se convierte en la esencia más problemática de la justicia en la posguerra. Se trata, en primer lugar, de decretar un olvido institucional como garantía de la paz y la restauración del orden y, en segundo lugar, de negar el pasado y con él la guerra, como si ella no hubiera ocurrido. La amnistía decretada por Mosquera el 30 de enero de 1863 es ilustrativa de esta funcionalidad (Uribe de Hincapié y López, 2008b, p. 110).

Como lo recuerda Iván Orozco Abad (2006), el siglo XIX colombiano "conoció el recurso a la amnistía como expediente para incrementar las bases de legitimidad del sistema político" (p. 214). Desde el inicio de la Guerra de los Supremos, en 1839, hasta la finalización de la guerra civil dirigida por Mosquera, en 1862, se produjeron 49 indultos y 10 amnistías de carácter nacional; innumerables indultos disuasivos y leyes de perdón concedidas por los gobiernos de los Estados y las provincias; y múltiples pactos, acuerdos de cese al fuego, armisticios, treguas y esposiones, firmadas por los ejércitos en el campo de batalla. El punto de partida de todos esos actos políticos fue la conveniencia pública de la paz y la necesidad de regular la guerra. En uno de los fragmentos de la comunicación enviada por Herrán al procurador, está claramente expresado el sentido asignado a estos instrumentos:

Comenzaré por deciros que yo, lejos de ser partidario de la impunidad, creo que la principal condición que debe exigirse de un gobierno es que dé garantías de justicia, porque la sociedad en que la justicia impera goza de toda la protección que las instituciones de los hombres puedan dar; mas no por eso convengo en que la concesión de una amnistía, tan amplia como permita nuestra Constitución, sea un acto injusto. Los jueces no pueden administrar justicia de otro modo que aplicando las penas señaladas por la ley a las personas que cometen los delitos que ella define [...] Pero vos no sois juez sino depositario de la clemencia nacional que se os confía para que la dispenséis en beneficio de la República. No debéis proceder como juez sino como hombre de Estado [...] (Herrán, 1861, pp. 82-83). 
La carta de Herrán da cuenta de dos distinciones adicionales: (1) que el derecho penal y ordinario empleado por los jueces es distinto del derecho de guerra, el cual debe adoptarse para regular y tramitar los conflictos armados internos, y (2) que la reconciliación es distinta de la justicia retributiva y, por tanto, ella es un asunto político no judicial que le compete al Estado. ${ }^{17}$ Justamente por eso, Herrán insiste en señalar que uno de los más grandes y difíciles problemas que debe afrontar una república dividida y fracturada por una guerra civil, es el de la justicia penal con aplicación a la política. Mientras los rebeldes son tildados, tipificados y sancionados como "reos por las leyes", el bando político que ellos representan los considera héroes, mártires y patriotas. La severidad del castigo puede producir deshonra y humillación y, como correlato, dar razones justas para nuevos levantamientos armados. Herrán lo expresa de una forma contundente cuando afirma que "cada gota de sangre derramada en los patíbulos produce mil rebeldes" (1861, p. 85). De nuevo, el general bogotano insiste en la necesidad de no criminalizar al enemigo aunque libre una guerra que no parezca justa, legítima y legal. En este sentido, su pensamiento hace eco a la idea de Vattel (1822), según la cual:

Sea que una república esté dividida en dos partidos que pretenden cada uno de por sí constituir el Estado entero, ó que un reino lo esté entre dos pretendientes de la corona, siempre resulta que la nación está dividida en dos partes, que se tratarán recíprocamente de rebeldes: he ahí dos cuerpos que pretenden ser absolutamente independientes, y que no tienen juez común. Deciden su querella por las armas, como lo harían dos naciones diferentes. La obligación de observar entre sí las leyes comunes de la guerra es pues absoluta, indispensable para los dos partidos, y la misma que la ley natural impone á todas las naciones de Estado á Estado (pp. 376-377).

En definitiva, la carta de Herrán pone de presente aquella particularidad colombiana que María Teresa Uribe (2011) identificó muy bien en sus trabajos sobre las guerras civiles decimonónicas: el lenguaje de la sangre derramada fue el hilo grueso que anudó

17 Al respecto, Giraldo anota que "toda justicia, si existe, nunca será suficiente cuando alguien está convencido de que la retribución debe ser el objetivo prioritario de los procesos políticos" (2017, p. 48). 
y articuló el despliegue trágico de acontecimientos muy distintos, ocurridos en guerras pasadas. En Colombia, el relato de la sangre derramada sustituyó otros relatos e hizo del discurso victimista un punto de convergencia identitario (pp. 147-183). Por ello, el general Herrán advierte que una paz que pretenda imponer a los vencidos castigos y reparación de perjuicios guiados por un espíritu de venganza, y no por el propósito de restablecer el orden fracturado, no siempre es una paz justa y no siempre es un beneficio, ni siquiera para el vencedor 【

\section{Referencias}

Arboleda, G. (1907). Revoluciones locales en Colombia. Martínez y Torres Editores e Imprenta del Departamento del Cauca.

Arboleda, G. (1990). Historia contemporánea de Colombia: Desde la disolución de la antigua República de ese nombre hasta la época presente. Banco Central Hipotecario.

Bello, A. (1840). Principios de Derecho de gentes. Imprenta de Bruneau.

Bobbio, N. (2000). El problema de la guerra y las vías de la paz (J. Binaghi, Trad.). Gedisa.

Camacho Roldán, S. (1983 [1863]). Cuestiones de Colombia con el Ecuador. En Escritos varios, tomo I (pp. 349-379). Editorial Incunables.

Camacho, C., Garrido, M. y Gutiérrez, D. (Eds.). (2018). Paz en la república: Colombia, siglo XIx. Universidad Externado de Colombia.

Canal, L. (1861). Proclama del gobernador del Estado de Santander e Intendente del distrito nacional a sus compatriotas, Pamplona, 3 de agosto de 1861. Citado por J. M. Quijano Otero (1982), Diario de la guerra civil de 1860 y otros sucesos políticos. Editorial Incunables.

Cuervo, Á. (1984 [1900]). Cómo se evapora un ejército. Editorial Incunables.

Giraldo Ramírez, J. (2001). El rastro de Caín: Una aproximación filosófica a los conceptos de guerra, paz y guerra civil. Escuela Nacional Sindical, Foro Nacional por Colombia y Viva la Ciudadanía. 
Giraldo Ramírez, J. (2009). Guerra civil posmoderna. Siglo del Hombre Editores, Universidad de Antioquia y Universidad EAFIT.

Giraldo Ramírez, J. (2017). Responsabilidad y reconciliación ante la justicia transicional colombiana. Editorial EAFIT.

González, F. (1997). Para leer la política: Ensayos de historia política colombiana. Cinep.

Guerrero, V. (2016). Guerras civiles colombianas: Negociación, regulación y memoria. Pontificia Universidad Javeriana.

Herrán, P. A. (1861). Carta política. Ciudadano Procurador General de la Nación. En J. Roa (1901), Política de Conciliación. Precedido de una noticia preliminar (pp. 75-96). Librería Nueva.

López, L. M. (2019). Lugareños, patriotas y cosmopolitas: Un estudio de los conceptos de patria y nación en el siglo xIx colombiano. Editorial EAFIT.

Mosquera, T. C. (1862). Amnistía otorgada a los beligerantes del Estado de Tolima el 19 de noviembre de 1862. En Codificación Nacional de todas las leyes de Colombia desde el año 1821 hechas conforme a la Ley 13 de 1912, tomo xx (pp. 187-189). Imprenta Nacional de Colombia.

Nieto, J. J. (1862). Bosquejo histórico de la revolución que regeneró el Estado de Bolivar. Imprenta de Ruiz e Hijo.

Orozco, I. (2005). Sobre los límites de la conciencia humanitaria: Dilemas de la paz y la justicia en América Latina. Temis, Universidad de los Andes.

Orozco, I. (2006). Combatientes, rebeldes y terroristas: Guerra y derecho en Colombia. Temis.

Ospina Rodríguez, M. (1860). Correspondencia entre el general Tomás Cipriano de Mosquera y el Doctor Mariano Ospina. Imprenta del Mosaico.

Ospina Rodríguez, M. (1861). Alocución del presidente de la Confederación. Imprenta de la Nación.

Ospina, J. (1927). Diccionario biográfico y bibliográfico de Colombia. Editorial Cromos.

Pinzón, C. (2017 [1864]). Sobre la Paz Pública. Co-Herencia, 14(26), 23-56. https://doi.org/10.17230/co-herencia.14.26.2. 
Prado, L. E. (2018). La paz conservadora, 1841-1849. En C. Camacho, M. Garrido y D. Gutiérrez (Eds.), Paz en la república: Colombia, siglo XIX (pp. 29-65). Universidad Externado de Colombia.

Samper, J. M. (1984 [1853]). Apuntamientos para la historia de la Nueva Granada. Editorial Incunables.

Sánchez, G. (2001). De amnistías, guerras y negociaciones. En G. Sánchez y M. Aguilera (Eds.), Memoria de un país en guerra: Los Mil Días, 18991902 (pp. 329-366). Planeta, Iepri, Universidad Nacional de Colombia.

Schmitt, C. (2002). El nomos de la Tierra en el Derecho de Gentes del "Jus publicum europaeum" (D. S. Thou, Trad.). Comares.

Schmitt, C. (2010). Ex captivitate salus. Experiencias de la época 1945-1947 (J. A. Pardos, Ed.). Trotta.

Uribe de Hincapié, M. T. (2001). Nación, ciudadano y soberano. Corporación Región.

Uribe de Hincapié, M. T. (2011). La filigrana de la paz: acuerdos, esponsiones, indultos y amnistías. En L. M. López (Ed.), Un retrato fragmentado. Ensayos sobre la vida social, económica y política de Colombia - siglos XIX y xx (pp. 186-208). La Carreta Editores, Alcaldía de Medellín.

Uribe de Hincapié, M. T. y López Lopera, L. M. (2006). Las palabras de la guerra: Un estudio sobre las memorias de las guerras civiles en Colombia. Instituto de Estudios Políticos de la Universidad de Antioquia, La Carreta Editores.

Uribe de Hincapié, M. T. y López Lopera, L. M. (2008a). La guerra por las soberanías: Memorias y relatos en la guerra civil de 1859-1862 en Colombia. Instituto de Estudios Políticos de la Universidad de Antioquia, La Carreta Editores.

Uribe de Hincapié, M. T. y López Lopera, L. M. (2008b). Los discursos del perdón y del castigo en la guerra civil colombiana de 1859-1862. Coherencia, 5(8), 83-114. https://bit.ly/39XDcMh.

Vattel, E. (1822). Derecho de gentes, ó Principios de la ley natural aplicados a la conducta é intereses de las naciones y de los príncipes. Tomo III. 
Imprenta de Lawalle. [Archivo PDF, Repositorio Institucional Universidad EAFIT]. http://hdl.handle.net/10784/1102.

Walzer, M. (2001). Guerras justas e injustas. Un razonamiento moral con ejemplos históricos (V. Beltrán Serrano, Trad.). Paidós.

\section{Archivos y periódicos}

Archivo General de la Nación [AGN]. Sección República, Fondo Secretaría Guerra y Marina, t. 1091, ff. 326-328.

Biblioteca Nacional de Colombia [BNC]. Fondo Pineda, f. 325, pieza 14, "Pedro Alcántara Herrán (1867). Un pensamiento".

Boletín Oficial (1861). N. ${ }^{\circ}$ 28. Armisticio de la Quebrada de Chaguaní, 10 de marzo de 1861.

Gaceta Oficial (1859). N. ${ }^{\circ} 2426$. Decreto declarando en estado de guerra a la Confederación, 5 de septiembre de 1859, p. 473.

Gaceta Oficial (1860). N. 2564. Contestación al general Tomás Cipriano de Mosquera, 21 de diciembre de 1860, p. 578.

Sala de Patrimonio Documental de la Universidad de Antioquia. Colección Hojas Sueltas, 1860 a 1865, doc. 72. 